\title{
Epistemologia da violência na educação no contexto da biopolítica contemporânea ${ }^{1}$
}

\author{
Epistemology of violence in education in the context of contemporary \\ biopolitics
}

\section{Epistemología de la violencia en la educación en el contexto de la biopolítica contemporánea}

\author{
Amarildo Luiz Treuisan ${ }^{2}$ \\ Universidade Federal de Santa Maria, Professor titular do Programa de Pós-Graduação em \\ Educação; Pesquisador do CNPQ
}

"Um indivíduo consegue hoje um diploma de curso superior sem nunca ter aprendido a comunicar-se, a resolver conflitos, a saber o que fazer com a raiva e outros sentimentos negativos." (Carl

Rogers).

Resumo: Com este estudo visou-se analisar a questão da violência do ponto de vista da sua relação com a ausência da preocupação, na educação, em trabalhar com situações de conflito. Para isso, investigou-se a tese da complementaridade entre epistemologia e hermenêutica, a verdade que vem das tradições e os achados empíricos, como forma de tencionar alguns conceitos correntes na relação entre filosofia e educação. Além disso, preocupou-se em descobrir como a temática da violência aparece e se constitui ponto de referência às ações educativas contemporaneamente e como é possível fazer frente a esse contexto a partir da aproximação entre racionalidade e historicidade. Com isso, propôs-se redimensionar a correlação da violência com a educação e a cultura.

Palavras-chave: Epistemologia. Hermenêutica. Violência. Biopolítica. Formação de professores.

\begin{abstract}
The article aims to analyze the issue of violence, from the point of view of its relation to the absence of concern, in education, in working with situations of conflict. For this, it investigates the thesis of complementarity between epistemology and hermeneutics, the truth that comes from the traditions and the

O artigo faz parte da pesquisa Violência na Educação: Repressão, Liberação ou Ausência de Limites?, aprovado no CNPq na chamada Bolsa PQ - 1D, com tempo de execução de 2017-2021. 2 Doutor em Educação pela Universidade Federal do Rio Grande do Sul; Mestre em Filosofia pela Universidade Federal de Santa Maria.
\end{abstract}


empirical findings, as a way of intending some current concepts in the relation between philosophy and education. In addition, it is concerned with discovering how the theme of violence appears and constitutes a point of reference for educational actions contemporaneously and how it is possible to face this context from the approximation between rationality and historicity. With this, it proposes to re-dimension the correlation of violence with education and culture.

Keywords: Epistemology. Hermeneutics. Violence. Biopolitics. Teacher training.

Resumen: El artículo trata de analizar la cuestión de la violencia, desde el punto de vista de su relación con la ausencia de preocupación, en la educación, en trabajar con situaciones de conflicto. Para ello, investiga la tesis de la complementariedad entre epistemología y hermenéutica, la verdad que viene de las tradiciones y los hallazgos empíricos, como forma de tender algunos conceptos corrientes en la relación entre filosofía y educación. Además, se preocupa en descubrir como la temática de la violencia aparece y se constituye punto de referencia a las acciones educativas contemporáneamente y como es posible hacer frente a ese contexto a partir de la aproximación entre racionalidad e historicidad. Con ello, propone redimensionar la correlación de la violencia con la educación y la cultura.

Palabras clave: Epistemología. Hermenéutica. Violencia. Biopolítica. Formación de profesores.

\section{CONSIDERAÇÕES INICIAIS}

A discussão sobre a violência está no coração das tragédias e catástrofes humanas (HOBSBAWM, 2003), especialmente quando existe descaso ou descuido para com a dor do outro. No Brasil, os dados da violência são cada vez mais alarmantes e revelam uma verdadeira catástrofe em curso. Segundo - Anuário Brasileiro de Segurança Pública de 2016 (FÓRUM BRASILEIRO DE SEGURANÇA PÚBLICA, 2016), o Brasil registrou mais vítimas de mortes violentas intencionais (ou pessoas assassinadas) em cinco anos do que a Guerra na Síria no mesmo período. Ou seja, enquanto na Síria, de março de 2011 a novembro de 2015, esse número era de 256.124, no Brasil, entre janeiro de 2011 e dezembro de 2015, atingiram-se 279.567 casos. Outros dados preocupantes trazidos no 
Anuário: houve 45.460 estupros em 2015, uma pessoa foi morta violentamente no País no mesmo ano a cada nove minutos, totalizando no referido ano 58.467 mortes. Segundo outras fontes, o Brasil é o sétimo país com o maior registro de mulheres vítimas de estupro e está entre os 10 maiores do mundo onde há mais casos de violência doméstica contra criança e adolescente (BURIGATO, 2014). ${ }^{3}$

Há um mapa que circula nas redes sociais e que tem chocado ainda mais a nossa autoestima, nesse quesito, já bastante afetada. Ele foi publicado pelo ONL Maps e mostra a soma dos assassinatos em diversos países do Globo, estando o Brasil acima dos índices de violência de vários países do mundo juntos, incluindo quase toda a Europa, parte do Oriente Médio e África, além de gigantescas nações como Canadá, Japão, Austrália e China.

Mapa 1 - Soma de assassinatos em diversos países do Globo



Fonte: Todos os... (2017).

Além de se relacionar ao estado atual de nossa sociedade, outro motivo para tratar a questão da violência pela investigação atual é sua relevância para o contexto brasileiro da educação, haja vista que, entre outras ocorrências, o Brasil é campeão mundial em violência nas escolas contra o professor. Enquanto

\footnotetext{
3 Cf. notícia publicada no site: < http://www.jornalopcao.com.br/reportagens/morte-garoto-bernardo-quais-os-limites-da-crueldade-humana-1 1093/>.
} 
a Coreia do Sul, a Malásia e a Romênia apresentaram índice zero de violência contra os professores, o Brasil, com sua cultura de tolerância zero, transformouse no campeão mundial em violência contra professores com 12,5 ocorrências de violência verbal ou de intimidação por semana. Os dados foram divulgados pela Organização para a Cooperação e Desenvolvimento Econônico (OCDE), e o estudo, chamado de Teaching and Learning it International Survey (TALIS), foi baseado em um questionário internacional de larga escala que focava as condições de trabalho dos professores e da aprendizagem nas escolas, com o objetivo de formular políticas públicas a respeito do tema (GOMES, 2014). ${ }^{4}$

Segundo informações do Relatório da Situação Global sobre Violência Escolar e Bullying da Unesco de 2015, que mede o percentual de alunos em escolas secundárias onde se relatou que o bullying impediu o aprendizado dos alunos, o Brasil se encontra em $19^{\circ}$ lugar entre todos os países do mundo com maior incidência (LET'S DECIDE..., 2017).

Dados preocupantes como esses trazem inquietações não somente para o aparato de repressão e as autoridades da segurança pública, mas também para os teóricos das Ciências Humanas e Sociais. Chauí (2016), por exemplo, chegou a propor a revisão da tese da autocompreensão do brasileiro como cordial e acolhedor e sugerir uma nova chave de leitura, a de que a sociedade brasileira é violenta e autoritária. No entanto, mesmo assim, comenta Chauí (1999): "os meios de comunicação costumam referir-se à violência com as palavras 'surto', 'onda', 'epidemia', 'crise', ou seja, termos que indicam um fenômeno anômalo, passageiro e acidental." (ROSA; TASSARA, 2004, p. 3).

Mas por que esses dados assombrosos ainda persistem em nosso contexto? Como é possível existir sociedades com um índice de violência comparativamente irrisório em relação à nossa cultura? Que obstáculos dificultam o seu correto enfrentamento ou a sua superação em nosso caso? Será que a terminologia utilizada pela mídia para definir a violência não tem algo mais a nos dizer sobre o tema? Afinal, alguns dos termos nomeados na imprensa para explicar a generalização da violência - como surto, epidemia

\footnotetext{
4 Mais informações a esse respeito estão disponíveis em: < https://professorlfg.jusbrasil.com.br/ artigos/136798228/brasil-campeao-mundial-na-violencia-contra-professores > .
} 
ou crise - estão embasados no contexto biopolítico, uma vez que aproximam a violência do espectro de doença contagiosa no campo da saúde pública.

Estudos têm comprovado a proximidade histórica da educação e da escola com as práticas que produzem sacrifício e trauma. ${ }^{5}$ Parece que o ideal moderno de educar sem repressão não conseguiu superar a relação forçada entre professor e aluno, fruto da herança do passado. Manacorda (1995), por exemplo, procura demonstrar em seu famoso livro História da Educação que a convivência com a brutalidade não é somente algo próprio do mundo contemporâneo, ou que aconteceu depois que a escola se abriu à vida, como defende Mattéi (2002). Manacorda (1995, p. 43) aduz que a função educador já nasce sob o estigma do sacrifício e da violência: "Esses educadores arcaicos têm em comum algo de estranho: são pessoas que mataram ou tentaram matar e, por isso, tiveram que fugir de suas terras e procurar hospitalidade em outro lugar." Bordieu e Passeron vão dizer que a escola reproduz, de forma simbólica, a violência instituída no sistema. Para Comênio, a violência física não deixou de existir depois que passou a ser proibida, mas ela foi simplesmente substituída pela violência psicológica. Não é, portanto, de todo desesperador o quadro atual, quando nos deparamos com a violência intramuros da escola, uma vez que isso nunca deixou de existir do ponto de vista histórico. Mas o problema é que essa situação vem se agravando no Brasil nos últimos anos. Notícia recente publicada na Folha de São Paulo, por exemplo, comenta que a violência contra os professores na rede pública paulista aumentou exponencialmente, tendo um crescimento de 189 \% no último ano, chegando à média de três casos de docentes atacados no Estado a cada dois dias (CAVALCANTI, 2018).

Temos desenvolvido em nosso projeto de pesquisa Violência na Educação: Repressão, Liberação ou Ausência de Limites? ${ }^{6}$ a hipótese de que é justamente sob a influência de algumas teorias sobre a violência na educação,

\footnotetext{
5 Segundo Charlot (2002), a violência na educação não significa somente violência física, mas, sim, a violência que inclui golpes, ferimentos, roubos, crimes e vandalismos e sexual; incivilidades, que podem se expressar em humilhações, palavras grosseiras e falta de respeito; e a violência simbólica ou institucional compreendida, entre outras coisas, como desprazer no ensino, por parte dos alunos, e negação da identidade e da satisfação profissional, por parte dos professores.

6 A investigação busca evidenciar como seria a violência não coercitiva na educação e no que ela difere do conceito tradicional, violência esta reificada na educação via teorias referenciais dos fundamentos e práticas educacionais, contribuindo para a biopolítica da violência.
} 
como as de Manacorda, Bourdieu, Passeron e Comênio que conseguimos perceber o fenômeno da violência escolar ligado a seus fatores históricos, sociológicos e pedagógicos. Porém, essas teorias carecem de um déficit normativo, pois a violência não se restringe à esfera do direito, do instituído ou da "ditadura da presença" (AVELAR, 2009, p. 14), como bem demonstrou Walter Benjamin em seu famoso escrito Crítica da Violência, mas a ultrapassa. Por isso, o tema da violência na educação adquiriu, de certa forma, contornos negativos, e cremos ser isso que contribui, entre outros fatores, para afastar os educadores da reflexão sobre esse problema. De tal forma é evidente essa influência que não temos ferramentas adequadas para lidar com o problema em sala de aula, o que repercute, como exposto anteriormente, no alto índice de violência dos alunos contra os professores na escola pública brasileira hoje.

É por isso que a racionalidade, que pretende extrair dos fatos as verdades do seu operar, mostrou-se insuficiente para dar conta do fenômeno da violência em sua complexidade, porque perdeu o norte para onde conduzir a reflexão. Como complemento, surge a tendência da historicidade, a qual procura a verdade na história e nas tradições, prevendo que a força do passado se impõe como condição para a ocorrência do ato do conhecimento. No artigo, procuramos mostrar as limitações do pensamento epistemológico no tratamento do tema, mas não deixamos também de aventar a necessidade de avanço na discussão da historicidade, ao ponto de abarcar a dimensão da biopolítica. Desse modo, o processo epistemológico caminha conjuntamente ao histórico e cultural, no sentido de evitar aporias que obstaculizam o seu real enfrentamento. Aliamo-nos por esse caminho à tendência na discussão epistemológica contemporânea em direção a privilegiar a tese da confluência ou da complementaridade entre racionalidade e historicidade, compreensão e explicação, epistemologia e hermenêutica (BOMBASSARO, 2005).

Nesse sentido, o argumento que o artigo pretende colocar em discussão é o de que, mesmo com as melhores intenções, ainda estamos presos ao prolongamento (biopolítico) do paradigma epistemológico moderno, na medida em que, diante de um acontecimento trágico ou catastrófico, ${ }^{7}$ as perguntas

\footnotetext{
7 No campo das catástrofes naturais, é interessante a entrevista de Vagner Anabor, doutor em física e professor de Meteorologia da Universidade Federal de Santa Maria (UFSM/RS), concedida
} 
habituais a serem formuladas são, normalmente: quem são os culpados e por que eles ainda não foram presos? Ou seja, queremos identificar os responsáveis e afastá-los da nossa vista ou do nosso horizonte de convívio comum como se fossem vírus ou bactérias causadoras de todo mal, com o intuito de considerar o ambiente escolar como um lugar sagrado. Essa atitude evita de nos questionar sobre os fatores ou as causas mais profundas que geraram o fenômeno ou que poderiam preveni-lo para que não mais ocorresse. Desse modo, estamos ainda atrelados ao esquema da violência mítica, da qual falava Benjamin no seu Crítica da Violência; não estamos operando com o conceito de violência divina ou revolucionária. ${ }^{8}$ Portanto, a proposição de um complemento entre a leitura da violência, pelo viés do encontro entre a epistemologia e a hermenêutica, é o que será visto a seguir. Como afirma Debarbieux (2002, p. 82), "a violência tem uma história, [...] ela não foi simplesmente uma explosão inesperada: ela é previsível, pois foi construída socialmente." Afinal, a busca da aproximação entre a verdade que vem dos fatos e a verdade das tradições na compreensão do fenômeno da violência, a sua compreensão e explicação ao mesmo tempo, ainda é um desafio a cumprir.

\section{O PARADOXO EPISTEMOLÓGIICO DA UIOLÊNCIA NA EDUCAÇÃO}

A epistemologia é um discurso diferente de outras áreas da Filosofia que se constituem disciplina, como a Ética, a Estética, a Filosofia da História

\footnotetext{
à IHU On-Line, sobre a ocorrência do evento extremo da microexplosão em forma de tornado, no dia 12/03/2017, na região serrana de São Francisco de Paula, no Rio Grande do Sul. Segundo ele, a questão mais urgente a ser discutida não é que tipo de fenômeno ocorreu, mas se seria possível prevê-lo e o que poderia ser feito antecipadamente. Nesse sentido, adverte: "A sociedade gaúcha precisa avançar nessa discussão, porque sempre que acontece um evento desses, a discussão se concentra nisto, ou seja, em se perguntar que tipo de evento ocorreu. Mas essa discussão não traz o retorno necessário para a nossa comunidade. $\bigcirc$ que traria retorno é uma discussão acerca do que seria preciso fazer para prever e antecipar esse tipo de fenômeno", avalia. Segundo ele, a pergunta central a ser feita no Rio Grande do Sul é: "Por que ainda não temos um serviço de previsão do tempo que seja capaz de prever esses fenômenos?" (FACHIN; SANTOS, 2017).

8 No artigo Crítica da Violência, Benjamin (1996) defende que a violência mítica está presa à relação meios e fins, por isso ela opera largamente no sistema, fazendo parte inclusive dos órgãos ou aparatos de repressão. Pelo contrário, a violência divina se defrontaria com essa visão, na medida em que é puro meio, não se atém à dimensão instrumental da violência, sendo encontrada em algumas manifestações como a greve geral proletária e no trabalho do educador. Nas palavras de Avelar (2009, p. 10), "trata- se de um texto que oferece marteladas de razão crítica ao mítico tema da violência."
} 
ou a Cosmologia. Ela é antes um modo de investigação baseado em um problema no âmbito do idealismo, qual seja, o problema da realidade externa. Dependendo do país ou da cultura que a compreende, ela pode ser entendida também como Gnosiologia ou Teoria do Conhecimento. A sua importância é fundamental para várias áreas do saber e teve o seu auge durante o período moderno, quando se propôs a admitir como conhecimento somente o que corresponde aos critérios de clareza e distinção. Descartes se deparou com essa dificuldade e por isso apelou para a ideia do "gênio maligno", que poderia estar lhe sabotando essa possibilidade. Francis Bacon achava necessária uma verdadeira "assepsia epistemológica", a começar pelos ídolos ou fantasmas, miragens e ilusões que poderiam impedir a correta compreensão do real. Rorty (1988) nomeou essa investida do aparelho cognitivo, em buscar a clarificação e limpeza do conhecimento, como metáfora da "mente como espelho", pois, ao procurar fazer a purificação do saber, a mente exclui quaisquer obstáculos que poderiam obscurecer sua representação. Esse modo de operar o conhecimento na consciência chegou até Hegel, que estendeu o espelhamento do real ao ponto máximo do modo de operar próprio do espírito absoluto, capaz de compreender toda a realidade. Hegel, porém, estabeleceu igualmente as bases para uma nova compreensão do real, por intermédio do processo de reconhecimento recíproco, que ocorre mediado pela valorização da ideia de cultura, de formação e da historicidade humana. Daí em diante o paradigma epistemológico da representação se deparou com os seus limites e aporias.

O desafio maior para a abordagem epistemológica hoje é o de como fundamentar a interioridade como pedra angular do conhecimento, sendo que várias pesquisas, inclusive no campo psicanalítico, encontraram fontes anteriores de explicação dos fenômenos humanos, como o inconsciente. Habermas (1982) diz, a partir de Hegel, que a dificuldade da epistemologia ou teoria do conhecimento é como afirmar um conhecimento antes do conhecimento. Desse modo, aos poucos a epistemologia foi perdendo terreno para outras abordagens, transformando-se em metodologia científica, incorporada pela filosofia da ciência ou ainda pela análise da linguagem ou do discurso. Mas apesar de todas essas mudanças, a epistemologia ainda resiste bravamente em algumas áreas como a Educação e em algumas correntes das Ciências Sociais e Humanas. 0 limite da ideia da representação ainda é crucial para o entendimento da questão 
da violência provocada pelas tragédias e catástrofes, por exemplo, haja vista a apropriação que dela fez Adorno e alguns integrantes da Escola de Frankfurt.

A relação da ideia de representação com o trauma, a catástrofe, a formação cultural (Bildung) e a resistência impõe muitos desafios, ao ponto de se tornar, a partir das contribuições da teoria crítica da sociedade, um dos temas centrais para a educação contemporânea. Adorno (1995) já se perguntava sobre a mudança conceitual da relação puramente representativa para uma relação mais ampla do ser humano com o mundo. Especialmente, quando enunciou o princípio de que as bases para a educação, na época sob o signo de Auschwitz, exigem levantar quais elementos se tornaram decisivos para gestar a barbárie. Um tempo sob o impacto dessa catástrofe demanda, de acordo com a sua avaliação, questionar a frieza e a indiferença do comportamento para com o outro, tão comum nos campos de concentração em razão do fato de que os carcereiros justificavam suas ações de extermínio dizendo que estavam apenas "cumprindo ordens". Também seria importante atentar para a necessidade de "desbarbarização do campo", uma vez que a maioria dos que estavam nessas funções nos campos de concentração provinham do meio rural. Não há qualquer tipo de preconceito quanto a isso da parte de Adorno, o que ele quer é chamar a atenção para o fato de que foi justamente nesse meio que o projeto do Esclarecimento ou Iluminismo mais fracassou. Outra característica a ser trabalhada no ser humano decorrente dessas experiências traumáticas é "o caráter manipulador" e "a identificação cega com todos os coletivos". O caráter manipulador de Hitler por meio de seus gestos e da sua retórica proporcionou, por parte dos alemães, a adesão aos símbolos e a todos os demais rituais de submissão ao regime nazista. A "elaboração do passado" e, além disso, "indagar as metas educacionais de uma civilização tecnicista" decorrem também das experiências acumuladas em decorrência do enfrentamento dos problemas dos campos de concentração, o que exige repensar a relação do entendimento com o tempo histórico.

Porém, existe uma dificuldade epistemológica na obra de Adorno para levar adiante tais propostas, na medida em que há uma contradição até certo ponto evidente entre a crença no potencial da arte e da educação em contribuir para a prevenção às experiências traumáticas, como as do Holocausto, e, ao mesmo tempo, a impossibilidade de expressar ou representar 
tais ocorrências; essa contradição perpassa igualmente a literatura de Shoah ou literatura de testemunho dos campos de concentração.

Aqui há, portanto, um obstáculo epistemológico a ser transposto, o qual não se resolve simplesmente apelando para a "instância da prática", mas antes requer investigação. Por isso, questiona-se: como trabalhar pedagogicamente a prevenção à violência das tragédias e catástrofes na formação docente se, ao mesmo tempo, há uma impossibilidade para a sua representação? Talvez resida nessa pergunta um dos problemas básicos para que possamos aprender com essas ocorrências, na medida em que o trauma advindo desse estado de coisas acaba obstaculizando o devido conhecimento do ocorrido, seja por meio da função da arte, da literatura, seja mesmo pelo processo educacional. Para a psicanálise, o trauma traz a marca do excesso e extrapola os esquemas usuais de representação, e assim ele mina a capacidade de o indivíduo fazer "qualquer antecipação." (CANAVÊZ, 2015, p. 43). Com isso, a representação do horror paralisa o indivíduo a tal ponto que não consegue falar ou expressar a experiência ou, mesmo, permitir que isso aconteça de maneira a transformar essa experiência em aprendizado e, dessa forma, em uma nova conduta ou posicionamento perante o mundo. É desse paradoxo que advém o trauma, na medida em que este "desorganiza os esquemas defensivos dos quais o aparelho psíquico se utiliza." (CANAVÊZ, 2015, p. 43-44). Com situação semelhante já havia se deparado Walter Benjamin, quando observou que os soldados voltavam emudecidos das batalhas da Primeira Guerra Mundial (BENJAMIN, 1996). Regressavam mais pobres em experiências, incapazes de expressar pela linguagem o impossível que haviam testemunhado, pois a linguagem encontrara aí o seu limite. Mas talvez a biopolítica possa auxiliar a entender o por que tal empreendimento, na contemporaneidade, não se ausentou por completo de nosso contexto, mas, ao contrário, tomou proporções inauditas.

\section{BIOPOLÍTICA DA UIOLÊNCIA NA EDUCAÇÃO}

Honneth (201 1, p. 106) deu o tom para a compreensão da mudança contemporânea em termos de diagnóstico de época, quando assim se expressa: 
Con la toma de poder de los nacionalsocialistas en Alemania y al conocerse paulatinamente la extensión del terror en la Unión Soviética, comienza un cambio profundo dentro de esta figura de diagnóstico de la época: poco a poco ocupa el centro aquella convergencia que parece existir entre el despotismo fascista y el sistema de poder estalinista. Bien pronto no se encuentra ninguna teoría com sensibilidad filosófico-social, que no vea en la posibilidad del totalitarismo el núcleo de las patologias sociales en la sociedad moderna. El modo económico capitalista, como critério de influencia determinante, pasa a segundo término y, en lugar de ello, se pone em primer plano la totalidad de la relación contemporánea con el mundo.

impulso das sociedades para se contrapor às soluções excludentes do Fascismo e do Nazismo é o grande desafio das teorias que pretendem refletir com sensibilidade os problemas sociais na contemporaneidade. Desse modo, a velha fórmula de atribuir todas as mazelas ao fundamento econômico da sociedade cai por terra e, em seu lugar, entra a relação ontológica do ser humano com a sua existência. No quesito violência, a tentativa de sua explicação relacionada a condições de miserabilidade econômica há muito já foi desabilitada. Surgiram outras explicações de cunho mais etnográfico ou, então, de gênero, como a que deriva o "gosto pela guerra" do ethos masculino, conforme argumentou Sontag (2014) no início de seu livro Ante el dolor de los demás, inspirada na obra Tres Guineas, de Virginia Wolff.

A biopolítica propõe um acréscimo a essa multiplicidade de fatores que emergem como causa da violência, na relação do ser humano com o seu meio de existência. Por analogia com o que ocorre com a epistemologia, a biopolítica transpôs para o universo biológico a mesma tentativa ou o mesmo ímpeto de identificar, fazer a limpeza do aparato cognoscitivo humano para que este tivesse mais clareza e distinção, fazendo de ora em diante uma assepsia externa ao sujeito. Foucault (1999) havia salientado em História da Sexualidade que a biopolítica ou a política da vida, que emergiu, de maneira positiva, a partir do século XVII, acabou ocasionando mais tarde muitas guerras e catástrofes. $\bigcirc$ que havia inicialmente funcionado muito bem no campo da saúde e da medicina, quando preveniu e controlou várias doenças contagiosas por meio da adoção de simples medidas de higiene, como lavar as mãos, e de profilaxia, como as vacinas, ao ser levado para o âmbito do que ele chamou de "corpo-espécie" ou do organismo social, tornou-se uma prática ou técnica 
de extermínio em massa. Os mesmos princípios de imunização e sobrevivência do organismo do indivíduo, que, ao se proteger contra as doenças, primeiro identifica, depois circunscreve, isola e mata o agente ou agressor externo, como os vírus e as bactérias, ao serem levados para a vida pública, ocasionaram a fobia da sociedade e, por consequência, do Estado com todos os diferentes.

Que fenômenos históricos se enquadram nesse espectro de análise? "Sem dúvida, o nazismo", cita Foucault (1999, p. 140):

\begin{abstract}
foi a combinação ingênua e mais ardilosa - ardilosa porque ingênua - dos fantasmas do sangue com os paroxismos de um poder disciplinar. Uma ordenação eugênica da sociedade, como o que ela podia comportar de extensão e intensificação dos micropoderes, a pretexto de uma estatização ilimitada, era acompanhada pela exaltação onírica de um sangue superior, esta implicava, ao mesmo tempo, o genocídio sistemático dos outros e o risco de expor assim mesmo a um sacrifício total.
\end{abstract}

Um pouco antes dessa reflexão, Foucault (1999, p. 140) já havia dado outro exemplo, ao afirmar claramente: " $\bigcirc$ racismo se forma nesse ponto (racismo em sua forma moderna, estatal, biologizante)." Essa realidade denunciada por Foucault leva a uma leitura que vai além da simples constatação do problema da violência, posto que se observa no tratamento do tema um encurtamento teórico ainda a ser enfrentado. Isso porque, se por um lado a abordagem da epistemologia de corte analítico refinou o nosso olhar em relação à ocorrência concreta e factual da violência, em larga medida, por outro, a sua simples adoção, sem levar em consideração os elementos históricos e culturais, circunscreveu o seu tratamento à tendência a reduzi-la "a fatos objetivos e objetificados." (DEBARBIEUX, 2002, p. 63). Logo, seu tratamento sem um questionamento anterior às premissas do paradigma que norteou a sua autocompreensão explicaria, em certo sentido, a nossa histórica ineficiência no combate a esse fenômeno generalizado.

$\bigcirc$ encontro entre racionalidade e historicidade no tratamento da questão da violência leva a induzir que o tratamento histórico do problema e os levantamentos sobre a questão da violência revelam questões estarrecedoras, uma vez que as estatísticas revelam dados alarmantes contra indivíduos de cor. De acordo com o Anuário Brasileiro de Segurança Pública de 2016, entre as 
vítimas de violência no Brasil, "54\% são jovens entre 18 e 24 anos [...] e 73\% são pretos ou pardos." (FÓRUM BRASILEIRO DE SEGURANÇA PÚBLICA, 2016, p. 6). Portanto, a criminalidade ou a violência não é um fenômeno do acaso ou algo simplesmente gratuito, mas revela uma intencionalidade biopolítica que está por trás. Ou seja, antes de epidemia ou surto, trata-se de uma verdadeira operação biopolítica de "purificação da raça", dado que se consideram esses indivíduos da população como seres inferiores que, portanto, devem ser exterminados. Se fosse outra etnia, de cor branca, a sofrer esse genocídio, será que a conivência com o problema e o tratamento dado pelas autoridades seria o mesmo? Conforme o Fórum Brasileiro de Segurança Pública (2016, p. 21 ): "E pouco importa que tais mortes sejam cometidas, em sua maioria, contra jovens negros das periferias brasileiras, já que estes compõem a parcela da população que fica invisível para a sociedade e para as políticas públicas." $\bigcirc$ mito de que o Brasil aboliu a escravidão de maneira cordial, "sem nenhuma gota de sangue", ou seja, sem violência alguma, ${ }^{9}$ ao contrário de outras nações, como os EUA ou a Argentina, que o fizeram debaixo de extrema violência e guerra, cai por terra, porque a nossa opção também foi pelo extermínio, mas por outras vias, digamos assim, em doses mais "socialmente aceitáveis".

Em decorrência do enredamento da epistemologia com os paradoxos da representação, a discussão contemporânea migrou para o campo das narrativas ou do testemunho (DE MARCO, 2004), uma vez que este havia sido sonegado pela tradição da epistemologia normal até então. ${ }^{10}$

\section{O PAPEL DO TESTEMUNHO: PRIMO LÉUI POR AGAMBEN}

Retomando o que foi exposto até o presente, a hipótese defendida no artigo é que o enfrentamento da violência tem sido realizado no prolongamento

\footnotetext{
9 Menino 23: Infâncias perdidas no Brasil, com direção de Belisario Franca, é um documentário interessante nesse sentido. Lançado no Brasil em 07 de julho de 2016, conta a história de meninos órfãos e negros vítimas de uma experiência criminosa de eugenia (MENINO 23..., 2016).

10 Ver a esse respeito o artigo Epistemologia do testemunho: o testemunho como fonte de justificação, de Ronaldo Miguel da Silva, disponível em <https://periodicos.ufsm.br/sociaisehumanas/ article/view/14821/pdf>.
} 
do paradigma epistemológico (biopolítico) que norteou a autocompreensão moderna do conhecimento. E este tem encontrado os seus limites, posto que diante de uma situação absurda, que desestabiliza as condições normais de representação, desabam os esquemas habituais de apreensão do real, e, em seu lugar, emerge o trauma. Cabe investigar as possibilidades da epistemologia de testemunho, como forma de "reconhecer o que as vítimas têm a dizer, e a reconhecer, portanto, seu poder de colocar seu sofrimento em palavras." (DEBARBIEUX, 2002, p. 67).

Giorgio Agamben é um continuador da discussão da obra de Foucault, em diálogo com outros autores como Hannah Arendt e Walter Benjamin. Nesse sentido vai dizer que a sobrevivência dos corpos é o lema da biopolítica contemporânea, cujo protótipo ou "tubo de ensaio" foram as experiências com os prisioneiros dos campos de concentração da Segunda Guerra. Eles eram figuras que apenas vegetavam. Agamben chama de "muçulmanos", ou seja, pessoas que não tinham o mínimo direito sobre os seus corpos e que viviam em permanente processo de aniquilação na zona cinzenta entre a vida e a morte, ou seja, eram meros sobreviventes ou "homo sacer".

O homo sacer representa o homem atual que normalizou a exclusão. filósofo italiano parte de Carl Schmitt, conservador jurista alemão do III Reich, que definia o soberano como aquele que decide sobre o estado de exceção, mas também de Walter Benjamin, que, em suas teses de filosofia da história, afirmava ter a exceção virado regra. Na interpretação de Agamben, vivemos tempos em que, apesar de todos os discursos tenderem para a inclusão, a exceção literalmente virou norma ou, melhor, normalizou-se a exceção, ficando a vida nua e sem proteção da cidadania oferecida pelo estado democrático de direito.

Se denominamos forma-de-vida a este ser que é somente a sua nua existência, essa vida que é sua forma e que permanece inseparável desta, então veremos abrir-se um campo de pesquisa que jaz além daquele definido pela intersecção de política e filosofia, ciências médico-biológicas e jurisprudência. Mas antes será preciso verificar como, no interior das fronteiras dessas disciplinas, algo como uma vida nua possa ter sido pensada, e de que modo, em seu desenvolvimento histórico, elas tenham acabado por chocar-se com um limite além do qual elas não podem prosseguir, a não ser sob o risco de uma catástrofe biopolítica sem precedentes. (AGAMBEN, 2010, p. 183). 
Ao refletir sobre a perspectiva de como narrar o trauma a partir da epistemologia do testemunho, baseado na obra de Primo Lévi, Agamben nota um impasse, pois quem chegou ao fundo daquela experiência, quem tocou o fundo da tragédia, não voltou para contar. E quem conta essas experiências não chegou a tocar esse fundo, o que deu margem para os historiadores revisionistas dizerem que tais fatos não ocorreram. Dessa forma, estamos novamente enredados no mesmo paradoxo da representação, conforme advertia Adorno.

A saída, para Agamben, é explorar o testemunho não como ato ou fato já dado, e que precisa ser conhecido, mas como potência de algo que ainda não se sucedeu, no sentido de falar por proximidade da experiência radical dos que não sobreviveram. Nesse sentido, ele busca compreender a estrutura do testemunho, que explora as potencialidades da linguagem entre o dizível e o indizível, como possibilidade de falar do impossível que foi Auschwitz.

\begin{abstract}
El descubrimiento inaudito que Levi realizó em Auschwitz se refiere a una matéria que resulta refractaria a cualquier intento de determinar la responsabilidad; ha conseguido aislar algo que es como un nuevo elemento ético. Levi lo denomina la "zona gris". En ella se rompe la larga cadena que une al verdugo y a la víctima"; donde el oprimido se hace opressor y el verdugo aparece, a su vez, como víctima. Una gris e incessante alquimia en la que el bien y el mal y, junto a ellos, todos los metales de la ética tradicional alcanzan su punto de fusión. (AGAMBEN, 2002, p. 20).
\end{abstract}

A experiência a que Lévi se reporta aqui como "zona gris", segundo Agamben, é a do Sonderkommando, um grupo ou "esquadra especial" de deportados ou prisioneiros designados pela SS nos campos de concentração para realizar tarefas de gestão das câmeras de gás e os crematórios. Ou seja, a tarefa desses prisioneiros era comandar os rituais de extermínio de colegas, exercendo um poder que era em princípio confiado aos carrascos. Essa revelação do testemunho de Lévi desvela uma região da ética que não é para além do bem e do mal, como falava Nietzsche, como território do superhomem. Mas algo aquém do humano, no nível infra ou anterior ao humano e que não foi tematizado pela ética até o momento. E essa é a aporia de Auschwitz de que falavam Adorno e Benjamin e agora o próprio Agamben (2002, p. 9): "la no coincidencia entre 
hechos y verdad, entre comprobación y comprensión." É nesse contexto dos campos de concentração que Agamben termina afirmando que a vida ficou nua.

Essa constatação vai ao encontro igualmente do que expressa Mattéi (2002), de que existe uma barbárie interior, que põe em xeque as concepções históricas que supunham que a barbárie poderia ser circunscrita aos muros fora da cidade ou dos reinos. Daí a necessidade de construir muros altos nos limites da cidade ou na divisão entre países, pois a barbárie vinha sempre de fora ou, como define a biopolítica, de inimigos ou agressores externos (vírus e bactérias). Essa abordagem também vai ao encontro do que se convencionou chamar, a partir dos anos 1960 e 1970, de "novo paradigma da violência", que, em razão do esvaziamento ideológico da sociedade, não apresenta mais um inimigo explícito (WIEVIORKA, 1997; PEREIRA COSTA, 2007). É nesse contexto que o inimigo se torna o terrorismo, pois ele não apresenta rosto, não é declarado. Assim como no filme Independence Day os responsáveis pela catástrofe foram seres alienígenas, o discurso construído por George Bush na ocasião da queda das Torres Gêmeas atribuiu esse evento a um inimigo externo: os terroristas islâmicos, que viviam à margem do capitalismo e da razão. Ora, nada mais contra essa lógica do que a constatação da teoria crítica da Escola de Frankfurt, quando percebeu que o mito andava pari passu com a razão.

Se o novo paradigma da violência representa uma crítica ao esvaziamento da modernidade (PEREIRA COSTA, 2007, p. 43), pode-se compreender o movimento das literaturas que problematizam e relatam a catástrofe como uma reação à filosofia hegeliana da representação e da consciência?Žižek (2013, p. 96) concordaria com isso, pois se trata, segundo ele, de "uma reação contra essa totalidade da automediação conceitual absoluta, contra esse Espírito onipotente que a tudo consome [...], o que significa, entre outras coisas, que a arte adquire seus direitos contra a filosofia."

\section{CONCLUSÃO}

Neste estudo a preocupação foi expor o tema da violência das tragédias e catástrofes que acometem o contexto contemporâneo segundo a 
noção do paradoxo epistemológico presente na obra de Adorno e Benjamin e, a seguir, na biopolítica de Michel Foucault e Giorgio Agamben. Por intermédio de uma imersão na obra desses autores, buscamos alguns elementos para repensar os desafios da educação no sentido de perceber a violência no contexto das tragédias e catástrofes biopolíticas que nos assomam a todo momento, especialmente via tecnologias da informação e comunicação.

Por isso analisamos a desorganização do paradigma epistemológico da representação como algo advindo do paradoxo do trauma provocado por esses eventos extremos; essa desordem é decorrente do enfrentamento de uma situação de violência limite por que passa o indivíduo. Há, portanto, a necessidade de transitar para o contexto da narrativa ou da literatura de testemunho, como forma de melhor elaborar a relação do indivíduo com o choque advindo do enfrentamento desses casos extremos, acompanhando o descentramento da discussão do campo epistemológico para o ético.

Assim, no artigo propôs-se repensar a confluência entre racionalidade e historicidade, compreensão e explicação no que diz respeito ao tratamento do tema da violência que aflige a educação. Nesse sentido, a investigação buscou alguns elementos para se repensar a violência a fim de refletir a possibilidade de compreendê-la por intermédio da tese da complementaridade entre epistemologia e hermenêutica. Não se trata, obviamente, de uma substituição de paradigma epistemológico pelo historicista simplesmente, mas é preciso perceber uma articulação histórico e dialética entre eles (TREVISAN, 2006), procurando a sua necessária complementação. $\bigcirc$ objetivo é analisar a relação da educação com a questão da violência e a cultura, especialmente a ausência de ferramentas de compreensão, na educação, para trabalhar com situações de violência e/ou conflito.

Ao contrário do que propõe a narrativa da biopolítica, os comportamentos violentos geralmente têm origem social - são comportamentos aprendidos. Como diz Debarbieux (2002, p. 75), "se a violência é construída, então ela pode ser desconstruída", o que deixa aberta a porta para pensarmos em soluções para além dos esquemas usuais de adoção da repressão, liberação ou ausência da colocação de limites (DEBARBIEUX; BLAYA, 2002; GONÇALVES, 2002), como acontece largamente na educação atualmente. Se 
a violência é um comportamento aprendido socialmente, é preciso desaprender a violência na linguagem do reconhecimento, como bem demonstrou Honneth a partir de Hegel. Ou seja, trata-se de reaprender o testemunho de vida a partir da linguagem do amor, da estima e da solidariedade. Essa é uma luta histórica que envolve a humanidade desde a origem, vivida sob os auspícios da razão, quando na Grécia Antiga se opunham "violência e logos, força e razão" (DEBARBIEUX; BLAYA, 2002, p. 18) ou civilização e barbárie.

Por esse caminho seria preciso desvendar o papel da família, da escola e da sociedade em cada caso, em que cada instância está falhando, principalmente no sentido de considerar o outro como um estorvo ou um vírus, algo que precisa ser exterminado, seguindo os preceitos da biopolítica. ${ }^{11}$ Também, por uma concepção de homem e mulher e de que mundo a humanidade quer habitar, a qual passa por uma redefinição da compreensão da violência como puro meio ou a violência que se enquadra na lógica entre meios e fins, como já criticava Walter Benjamin.

Desse modo, a formação do espírito é compreendida não somente sob a forma da resistência, como um polo oposto do conhecimento, mas como "entre" as figuras do espírito, algo que se torna não apenas contrário, mas imprescindível para o trânsito de uma figura (do espírito) a outra. Não se trata, na linguagem da fenomenologia do espírito, de paralisar a discussão na negação da afirmação e nem na negação da negação, mas de afirmação da negação, incorporando-a. Nesse ponto há uma complementação do paradigma puramente epistemológico pelos aportes da história da arte, da ética, da psicanálise, da literatura e também da filosofia e da educação, como propunha a teoria crítica da sociedade, pois essas áreas têm muito a contribuir no sentido da elaboração crítica do passado traumático. Ao incorporar o negativo, destaca-se

\footnotetext{
11 Reportamo-nos aqui, a título de exemplo, ao famoso caso de homicídio premeditado de um menino de 11 anos, ocorrido em 14 de abril de 2014, o qual estudava em uma escola da cidade de Três Passos, RS, Brasil, por aqueles que, supostamente, deveriam ser seus cuidadores e protetores. O corpo do menino Bernardo Boldrini foi encontrado enterrado em um matagal na área rural de Frederico Westphalen, a cerca de 80 quilômetros da cidade de Três Passos (RS), onde ele residia com sua família. De acordo com as notícias veiculadas na mídia, a Polícia Civil informou tratar-se de caso de homicídio premeditado, fato que abalou o País. Segundo as investigações, o garoto foi morto com uma superdosagem de sedativo, seguida de uma injeção letal e, para favorecer a ocultação do cadáver, foi jogada soda cáustica sobre o corpo. De acordo com a acusação do Ministério Público, entre as causas prováveis, o menino representava "um estorvo" para a nova unidade familiar estabelecida entre o pai e a sua madrasta (PIRES, 2014).
} 
a importância dos saberes ligados à prevenção da violência. E caso o fenômeno já tenha ocorrido, há necessidade de saberes expressivos ou narrativos, pois sem isso não haverá comunicação da experiência vivida, menos ainda haverá aprendizado decorrente desse sofrimento, e, assim, continuaremos presos à "catástrofe da formação", de que falava Hegel na Fenomenologia do espírito.

\section{REFERÊNCIAS}

ADORNO, T. Educação e Emancipação. Tradução Wolfgan Leo Maar. São Paulo: Paz e Terra, 1995.

AGAMBEN, G. Homo Sacer: o poder soberano e a vida nua I. 2. ed. Belo Horizonte: Ed. UFMG, 2010.

AGAMBEN, G. Lo que queda de Auschwitz. El archivo y el testigo. (Homo Sacer III). Tradução Antonio Gimeno Cuspinera. Valencia: Guada Impressores, 2002.

\section{AVELAR, I. O Pensamento da Violência em Walter Benjamin e Jacques}

Derrida. 2009

BENJAMIN, W. Crítica da violência. In: Escritos sobre mito e linguagem. São Paulo: Duas Cidades; Editora 34, 2013. p. 121-156.

BENJAMIN, W. Obras escolhidas: magia e técnica, arte e política. São Paulo: Brasiliense, 1996.

BOMBASSARO, L. C. Entre epistemologia e hermenêutica - a questão da racionalidade e da historicidade do conhecimento e o debate sobre a tese da complementaridade. In: TREVISAN, A. L.; ROSSATTO, N. D. (Org.). Filosofia e Educação: confluências. Santa Maria: FACOS - UFSM, 2005. p. 183-196.

BURIGATO, T. Morte do garoto Bernardo: quais os limites da crueldade humana? Jornal Opção, 26 jul. 2014. Disponível em: <http://www.jornalopcao. com.br/reportagens/morte-garoto-bernardo-quais-os-limites-da-crueldade-humana-1 1093/> . Acesso em: 14 maio 2017.

CANAVÊZ, F. $\bigcirc$ trauma em tempos de vítimas. Ágora, Rio de Janeiro, v. 18, n. 1, p. 39-50, jan./jun. 2015.

CAVALCANTI, T. Casos de agressão a professores crescem 189\% no estado de São Paulo. Folha de S. Paulo. Disponível em: <https://wwwl folha.uol.com. br/educacao/2018/08/casos-de-agressao-a-professores-crescem-189-no-estado-de-sao-paulo.shtml>. Acesso em: 07 ago. 2018. 
CHARLOT, B. Violência na escola: como os sociólogos franceses têm abordado essa questão. Interfaces. Sociologias, Porto Alegre, ano 4, n. 8, p. 432443, jun./dez. 2002.

CHAUI, M. Sociedade brasileira: violência e autoritarismo por todos os lados. Entrevista concedida a Juvenal Savian Filho e Laís Modelli. Carta Maior, 23 fev. 2016. Disponível em: < http://www.cartamaior.com.br/?/Editoria/Politica/ Sociedade-brasileira-violencia-e-autoritarismo-por-todos-os-lados/4/35548> . Acesso em: 15 maio 2017.

CHAUI, M. Uma ideologia perversa. Folha de São Paulo, São Paulo, 14 mar. 1999. Caderno Mais!, p. 3.

DE MARCO, V. Literatura de testemunho e violência de estado. Lua Nova Revista de Cultura e Política, CEDEC, n. 62, p. 45-68, 2004.

DEBARBIEUX, E.; BLAYA, C. (Org.). Violência nas escolas e políticas públicas. Brasília, DF: UNESCO, 2002.

DEBARBIEUX, E. "Violência nas escolas": divergências sobre palavras e um desafio político. In: DEBARBIEUX, E.; BLAYA, C. (Org.). Violências nas escolas e políticas públicas. Brasília, DF: Unesco, 2002. p. 59-92.

FACHIN, P.; SANTOS, J. V. Entrevista especial com Vagner Anabor. Revista IHU On-Line. Disponível em: <http://www.ihu.unisinos.br/espiritualidade/159-entrevistas/565806-monitoramento-de-eventos-extremos-as-escolas-de-meteorologia-nao-podem-assumir-a-funcao-dos-gestores-publicos-entrevista-especial-com-vagner-anabor >. Acesso em: 15 maio 2017.

FÓRUM BRASILEIRO DE SEGURANÇA PÚBLICA. Anuário brasileiro de segurança pública 2016. Disponível em: <http://www.forumseguranca.org. br/storage/10 anuario site 18-11-2016-retificado.pdf > .

Acesso em: 14 maio $20 \overline{1} 7$.

FOUCAULT, M. História da sexualidade I: A vontade de saber. 13. ed. Rio de Janeiro: LmortoGraal, 1999.

GOMES, L. F. Brasil: campeão mundial na violência contra professores. Jusbrasil Destaques, 2014. Disponível em: <https://professorlfg.jusbrasil.com.br/artigos/ 136798228/brasil-campeao-mundial-na-violencia-contra-professores $>$. Acesso em: 15 maio 2017.

GONÇALVES, L. A. O. Narrativas da violência no meio escolar: limites e fronteiras, agressão e incivilidade. Pro-posições, v. 13, n. 3 (39), p. 85-98, set./ dez. 2002.

HABERMAS, J. Conhecimento e interesse. Rio de Janeiro: Zahar, 1982. 
HEGEL, G. W. F. Fenomenologia do espírito. 5. ed. Tradução Paulo Menezes. Petrópolis: Vozes; Bragança: Ed. Universitária São Francisco, 2008.

HONNETH, A. La sociedad del desprecio. Edición y traducción de Francesc J. Hernàndez y Benno Herzog. Madrid: Trotta, 2011 .

HOBSBAWM, E. Era dos extremos: o breve século XX (1914-1921). São Paulo: Companhia das Letras, 2003.

GOMES, L. F. Brasil: campeão mundial na violência contra professores.

Jusbrasil. Disponível em: <https://professorlfg.jusbrasil.com.br/artigos/136798228/brasil-campeao-mundial-na-violencia-contra-professores > . Acesso em: 15 maio 2017

LET'S DECIDE how to measure school violence. Policy Paper 29, Jan. 2017. Disponível em: <http://unesdoc.unesco.org/images/0024/002469/246984E. pdf $>$. Acesso em: 15 maio 2017.

MANACORDA, M. A. História da educação: da antiguidade aos nossos dias. São Paulo: Cortez, 1995.

MATTÉI, J.- F. A barbárie interior. Ensaio sobre o i-mundo moderno. São Paulo: Ed. UNESP, 2002.

MENINO 23: Infâncias perdidas no Brasil. Direção de Belisario Franca. Fotografia de Thiago Lima, Mário Franca e Lula Cerri. Produção: GIROS, 07 jul. 2016. Disponível em: <http://www.menino23.com.br/menino-23/>. Acesso em: 31 maio 2017.

PEREIRA COSTA, Y. M. Crash e o novo paradigma da violência. Outros tempos, v. 1, p. 32-45, 2007. Edição especial.

PIRES, S. 'Não tenho dúvida', diz familiar sobre pai de Bemardo ser mentor; ouça. Globo.com, 15 maio 2014. Disponível em: < http://gl.globo.com/rs/rio-grande-do-sul/ caso-bemardo-boldrini/noticia/2014/05/nao-tenho-duvida-diz-familiar-sobre-pai-ser-mentor-de-morte-de-bemardo.html>. Acesso em: 15 maio 2017.

RORTY, R. A filosofia e o espelho da natureza. Lisboa: Publicações D. Quixote, 1988.

ROSA, E. M.; TASSARA, E. T. de O. Violência, ética e direito: implicações para o reconhecimento da violência doméstica contra crianças. Psicologia Ciência e Profissão, v. 24, n. 3, p. 34-39, 2004.

SILVA, R. M. de. Epistemologia do testemunho: $\bigcirc$ testemunho como fonte de justificação. Problemata: Revista Internacional de Filosofia, v. 5, n. 2, p. 221-251, 2014. Disponível em: <https://periodicos.ufsm.br/sociaisehumanas/ article/view/14821/pdf>. Acesso em: 13 maio 2017. 
SONTAG, S. Ante el dolor de los demás. 3. ed. Barcelona: Debolsillo, 2014.

TODOS OS países em azul no mapa somam a mesma quantidade de homicídios do Brasil. Implicante. Disponível em: <https://www.geledes.org.br/ todos-os-paises-em-azul-no-mapa-somam-mesma-quantidade-de-homicidios-do-brasil/> . Acesso em: 15 maio 2017.

TREVISAN, A. L. Paradigmas da filosofia e teorias educacionais: novas perspectivas a partir do conceito de cultura. Educação \& Realidade, v. 31, n. l, p. 23-36, jan./jun. 2006.

\section{ZAMBIAZI, J. L. A (des)positivação na formação do educador em Ciên-} cias Exatas e Naturais. 2000. Dissertação (Mestrado em Educação)-Universidade Federal de Santa Catarina, Florianópolis, 2000. Disponível em: <https://repositorio.ufsc.br/bitstream/handle/123456789/78423/175679. pdf? sequence $=1>$. Acesso em: 15 maio 2018.

ŽIŽEK, S. Menos que nada: Hegel e a sobra do materialismo dialético. Tradução Rogério Bettoni. São Paulo: Boitempo, 2013.

WIEVIORKA, M. O novo paradigma da violência. Tempo Social. Revista de Sociologia da USP, São Paulo, v. 9, n. 1, p. 5-41, maio 1997. Aceito em: 09 de agosto de 2018

Endereço para correspondência: Rua Heitor da Graça Fernandes, 280, Apto. 401, Bairro Camobi, 97105-170, Santa Maria, Rio Grande do Sul, Brasil; trevisanamarildo@gmail.com 